\title{
Gestão dos sistemas municipais de educação: planejamento e equilíbrio federativo em questão
}

Eliza Bartolozzi Ferreira ${ }^{a}$

\section{Resumo}

Este texto tem por finalidade a análise sobre os desafios do planejamento educacional na gestão do sistema municipal de educação. Especificamente, o objetivo é apreender se a condução do Plano de Ações Articuladas segue a trilha da hegemonia e centralidade do Estado e/ou se constitui um meio de dar voz à sociedade civil na condução da gestão pública. Por meio de um estudo de caso, observa-se que o cumprimento do PAR é dependente de um equilíbrio na execução de ações centralizadoras e descentralizadoras de modo a favorecer o fortalecimento das competências dos municípios no planejamento educacional. Ademais, é fundamental que seja cumprido o papel nuclear do Estado, no sentido de colaborar para a superação das dificuldades orçamentárias, gestionárias e pedagógicas que afligem os entes administrativos locais. Talvez assim o planejamento educacional possa contribuir para o desejado equilíbrio federativo.

Palavras-chave: Planejamento. PAR. Sistema municipal de educação.

\section{Introdução}

Com a finalidade de aprofundar a reflexão acadêmica sobre os desafios do planejamento educacional, este artigo objetiva apreender se a condução do Plano de Ações Articuladas (PAR) segue a trilha da hegemonia e centralidade do Estado, e/ou se constitui um meio para dar voz à sociedade civil na condução da gestão pública. Parte-se do ponto de vista de que a ação educativa, em tese, não seria mero reflexo dos planos oficiais, tendo em vista que as metas de longo prazo nem sempre se sustentam no tempo da política, sofrendo modificações e adaptações. Concorrem ainda para isto as demandas oriundas de setores reivindicativos da sociedade, as quais são incorporadas em períodos de maior mobilização social.

\footnotetext{
a Universidade Federal do Espírito Santo - UFES, Programa de Pós-Graduação em Educação. Vitória, Espírito Santo, Brasil.
} 
Leva-se, ainda, em conta que as mudanças desencadeadas com a promulgação da Constituição Federal de 1988 deram espaço mais amplo à autodeterminação dos entes federados (estados e municípios).

O planejamento está intimamente ligado à própria estrutura do regime federativo e das condições por ele impostas no que diz respeito ao movimento de centralizaçãodescentralização administrativa e financeira. A tese de doutorado de Martins (2009) se propôs observar as relações entre o poder central e os entes federados brasileiros, mostrando que estas não tiveram uma evolução contínua e linear ao longo da história republicana, mas foram permeadas por momentos de maior ou menor centralização, compreendida como concentração de poder político e financeiro no governo central (União) ou de maior distensão em relação aos estados e municípios. Tanto no período do Império como no da República, até a redemocratização consolidada com a Constituição Cidadã de 1988, considerou-se a questão da autonomia municipal como um problema provincial/estadual e não federativo. Não havia autonomia para a organização da esfera: era comum que a esfera estadual aprovasse uma lei orgânica para o conjunto de seus municípios. Somente com a Carta de 1988 os municípios foram guindados a entes federativos com a outorga de elementos constitutivos do equilíbrio federativo e, portanto, da autonomia municipal (autogoverno, autolegislação, autoadministração).

Em 2007, o governo lançou o Programa de Aceleração do Crescimento (PAC), que buscou recuperar a capacidade de induzir o desenvolvimento de amplo espectro de setores fundamentais para a modernização da economia, adotando como estratégia, pela primeira vez em muitas décadas, o apoio à formação de capital da parte do setor privado e, simultaneamente, aumentar o investimento público em infraestrutura. Na sequência do PAC, o Ministério da Educação lançou o Plano de Desenvolvimento da Educação (PDE), com apresentação de um conjunto de programas sob a propositiva de assegurar a perspectiva sistêmica da educação.

Quando se examina as bases conceituais do PDE, surge uma questão referente ao modo operacional de conceber o "sistema educacional". Isto porque a multiplicidade de órgãos pode gerar heterogeneidade nos métodos e critérios para a consecução da assistência técnica aos municípios. No sentido que lhe dá Saviani (2008), o termo sistema, para além do seu uso indiscriminado, denota a reunião de várias unidades formando um todo,

[...] mas é preciso considerar que, para lá dessas acepções, o termo sistema denota um conjunto de atividades que se cumprem tendo em vista determinada finalidade. E isso implica que as referidas 
atividades são organizadas segundo normas decorrentes dos valores que estão na base da finalidade preconizada (SAVIANI, 2008, p. 60).

O pressuposto aqui adotado é que a complexidade da análise sobre a gestão do sistema municipal de educação não permite um tratamento como merecido nos limites deste artigo. Dessa forma, este texto se centra na discussão de dados da pesquisa "Gestão das políticas educacionais no espírito santo e seus mecanismos de centralização e descentralização: o desafio do Plano de Ações Articuladas (PAR)", financiada pelo CNPq. Apenas duas partes constituem este texto, além da introdução e considerações finais. A primeira parte constrói, por meio de análise documental, um pouco da história de criação do PAR; a segunda parte faz referência a um estudo de caso de implantação do PAR no Espírito Santo como meio de responder sobre a capacidade desta política em promover o equilíbrio federativo.

\section{Origem da política do Plano de Ações Articuladas (PAR)}

Por meio do Decreto $n^{0}$ 6.094, de 24 de abril de 2007 (BRASIL, 2007a), o então Presidente da República do Brasil - Luiz Inácio Lula da Silva (2003-2010), implantou o "Plano de Metas Compromisso Todos pela Educação" (Compromisso) em regime de colaboração com Municípios, Distrito Federal e Estados, devendo contar com a participação das famílias e da comunidade, mediante programas e ações de assistência técnica e financeira, como forma de buscar a mobilização social pela melhoria da qualidade da educação básica. O Decreto aponta 28 diretrizes para serem cumpridas pelos entes da federação para o alcance da qualidade da educação a ser aferida pelo Índice de Desenvolvimento da Educação Básica (IDEB). Em 2009, de acordo com documentos do Ministério da Educação (MEC), todos os entes da federação já haviam aderido ao Compromisso. Essa conquista demandou um esforço concentrado do então Ministro da Educação - Fernando Haddad -, conforme revela a citação abaixo.

Um ponto importante e que ajudou no processo de adesão ao Plano de Metas, diz respeito à realização de caravanas e eventos regionais para os municípios priorizados. Neste sentido, o Ministro da Educação em conjunto com sua equipe, e especialmente a secretária da SEB, percorreram as 27 Unidades da Federação com o propósito de conscientizar os gestores estaduais e municipais da importância desta nova política educacional (BRASIL, 2010, p. 19).

Na Seção II do referido Decreto, foi criado o Plano de Ações Articuladas (PAR), como o conjunto articulado de ações, apoiado técnica ou financeiramente pelo Ministério da Educação, que visa o cumprimento das metas do Compromisso e a observância 
das suas diretrizes. O PAR é a base para o estabelecimento do termo de convênio ou de cooperação entre a União e os estados e municípios, cujo procedimento de adesão deve ser formalizado pelo prefeito do município ou governador do estado ao assinar o Compromisso e realizar a Prova Brasil. Esses estados subnacionais deverão receber auxílio da equipe técnica do MEC que identificará as medidas mais apropriadas para a gestão do sistema, com vista à melhoria da qualidade da educação. Dessa forma, o MEC se propõe a dar assistência técnica ou financeira para implementação das diretrizes contidas no Compromisso.

Além do Decreto ${ }^{0}$ 6.094/2007 que visa regular o cumprimento das metas para o alcance da qualidade da educação, o então Ministro da Educação Fernando Haddad, no mesmo ano de 2007, lançou um livro (BRASIL, 2007b) com o objetivo de divulgar o Plano de Desenvolvimento da Educação (PDE). O livro expõe as razões, princípios e programas de sua gestão para a melhoria da qualidade da educação básica. O PDE propõe ser um plano executivo, constituído por programas divididos em quatro eixos norteadores: educação básica, educação superior, educação profissional e alfabetização; apresenta como essência a perspectiva sistêmica da educação, isto é, vê o ensino fundamental relacionado ao ensino superior, o incentivo à pesquisa influindo no ensino médio, o transporte escolar articulado com a remuneração dos professores. Dessa forma, com críticas formuladas à tradicional fragmentação das políticas educacionais, o PDE propõe o diálogo entre os entes federativos, com destaque para a necessária articulação entre a União, estados, Distrito Federal e municípios para a garantia do direito à educação no País. Segundo o livro (BRASIL, 2007b), isso significa compartilhar competências políticas, técnicas e financeiras para executar os programas e ações.

A União passou, com o PDE, a assumir mais compromissos perante os estados, os municípios e o Distrito Federal, para, respeitando os princípios federativos, dar unidade ao desenvolvimento da educação e corrigir as distorções que geram desigualdades (BRASIL, 2007b).

Como mecanismo de aferir o cumprimento das 28 diretrizes apontadas no Compromisso, o MEC promoveu uma alteração na avaliação nacional da educação básica com a criação da Prova Brasil. De acordo com Art. $3^{\circ}$ do Decreto ${ }^{\circ}$ 6.094/2007 (BRASIL, 2007a), o MEC buscou cruzar os resultados de desempenho escolar (Prova Brasil) e os resultados de rendimento escolar (fluxo apurado pelo censo escolar) em um único indicador de qualidade: o Índice de Desenvolvimento da Educação Básica (IDEB). O IDEB deve ser calculado e divulgado periodicamente pelo Instituto Nacional de Estudos e Pesquisas Nacionais (INEP), cujo cálculo é realizado por escola, por rede e para o próprio País. 
De acordo com o livro PDE (BRASIL, 2007b), as 28 diretrizes que orientam as ações do Compromisso foram definidas a partir de dois estudos realizados em parceria com organismos internacionais, em escolas e redes de ensino cujos alunos demonstraram desempenho acima do previsto, consideradas variáveis socioeconômicas. O objetivo central dos estudos foi identificar um conjunto de boas práticas às quais poderia ser atribuído o bom desempenho dos alunos. Essas boas práticas foram traduzidas nas 28 diretrizes.

Em 20 de junho, portanto dois meses após sair o Decreto 6.094/2007, o então Ministro Fernando Haddad assinou a Resolução FNDE n $n^{\circ}$ 029/2007 (BRASIL, 2007c) que estabeleceu os critérios, parâmetros e procedimentos para operacionalização da assistência financeira aos entes da federação no âmbito do Compromisso. Nessa Resolução e em seus anexos, o FNDE estabeleceu os municípios prioritários para receber a assistência técnica e financeira; os instrumentos a serem adotados e os eixos temáticos do PAR: gestão educacional, formação de professores e dos profissionais de serviço e apoio escolar, práticas pedagógicas e avaliação e infraestrutura física e recursos pedagógicos. Ademais, definiu uma Comissão Técnica composta pelo MEC e FNDE responsável por analisar e aprovar o PAR de cada ente da federação e uma equipe de avaliação do cumprimento das metas de aceleração do desenvolvimento da educação, constantes do Plano de Ações Articuladas (PAR). Segundo a Resolução, a equipe de avaliação deverá ser composta por um projeto amplo, envolvendo parcerias com a União Nacional de Dirigentes Municipais de Educação (UNDIME), Conselho dos Secretários Estaduais de Educação (CONSED), União Nacional dos Conselhos Municipais de Educação (UNCME), Fórum Nacional dos Conselhos Estaduais de Educação, Instituições de Ensino Superior e outros órgãos de representação ou entidades especializadas para este fim.

Após exatamente dois meses, o Ministro da Educação assinou outra Resolução de $\mathrm{n}^{\circ}$ 047/2007 que alterou dispositivos da anterior, revelando prováveis tensões ocorridas entre as ações do MEC com os governos estaduais (especificamente o Consed). É certo que o Compromisso tinha interesse de atingir os municípios e, por isso, a Resolução ${ }^{\circ} 029$ (BRASIL, 2007c) quase não fez menção aos estados, o que ocorreu apenas no art. 15, quando afirmou a possibilidade dos estados colaborarem com assistência técnica e/ou financeira adicionais para execução e monitoramento dos convênios firmados com os municípios, sendo essa participação formalizada na condição de partícipe ou interveniente (Parágrafo único).

Já na Resolução ${ }^{\circ}$ 047, pode-se observar detalhamentos sobre a inclusão dos estados no cômputo da assistência técnica e financeira do FNDE a ponto de criar um item referente às condições de participação dos estados e Distrito Federal, 
antes inexistente, passando a redação a constar de outro item para "das condições de participação dos municípios". Com as alterações feitas pela nova Resolução, os estados e o Distrito Federal (DF) conseguiram se impor e destacar o seu lugar de poder no regime federalista brasileiro quando o art. 15 passa a vigorar com a seguinte redação: "Os Estados e o Distrito Federal serão comunicados sobre a programação das atividades que resultarão na visita técnica e sobre o regime de colaboração" (BRASIL., 2007c, p. 2). Ou seja, a partir da Resolução 047/2007, o MEC/FNDE deveria comunicar aos governadores quando o seu município receber a equipe para elaborar o PAR e sobre os termos concedidos no convênio firmado. Ademais, os estados e o DF passaram a poder solicitar consultoria técnica ao MEC na elaboração do PAR.

A importância de destacar as alterações feitas na legislação está em observar um exemplo de como se processam as negociações para implantação de uma política educacional em um país de regime federativo do modelo do Brasil com municípios portadores de autonomia, conforme preconizado pela Constituição Federal de 1988.

Mas, de acordo com os documentos consultados, o nascimento do Compromisso se deu a partir da reunião de alguns poucos técnicos em Brasília. A consultora do MEC, Robl (BRASIL, 2010) descreveu o processo no "Documento Técnico contendo o histórico acerca da criação e implementação do Plano de Metas Compromisso Todos pela Educação e as perspectivas de continuidade". Para a consultora, um dos fatores que levou à criação do Compromisso foi a percepção do então presidente do FNDE, Daniel Balaban (2006-2011).

Um dos fatores que levou a criação do Plano de Metas Compromisso Todos pela Educação foi a percepção do presidente do FNDE, Daniel Balaban, quando através de estudos identificou que os municípios que apresentavam projetos ao FNDE, a fim de obterem recursos eram sempre os mesmos. De acordo com relatos do próprio presidente, em torno de $80 \%$ dos municípios brasileiros nunca sequer haviam apresentado projetos para obtenção de recursos, ou então, quando apresentavam, estes eram reprovados: ou pela forma ou pela inconsistência da proposta. Ou seja, aqueles municípios mais bem preparados, seja por sua capacidade técnica, seja pela facilidade na contratação de consultorias especializadas na confecção de projetos, sempre acabavam obtendo os recursos (cerca de $20 \%$ do total de municípios). E os demais, aqueles com baixa capacidade técnica ficavam a margem de conseguir qualquer forma de financiamento 
gerado pelas transferências voluntárias. O único acesso, até então era aquele garantido pelas transferências legais (BRASIL, 2010).

Por muito tempo, analistas críticos das políticas públicas apontaram que a prioridade na distribuição dos recursos financeiros sempre foi de natureza político-partidária e/ou pela intermediação de empresas de assessoria aos municípios mais experientes. Essa prática resultou na corrupção dos parcos recursos financeiros existentes para a educação e deveria incomodar muitos gestores mais comprometidos com a educação pública. É provável que isso tenha ocorrido na gestão de Balaban.

Segundo a Consultora do MEC, em fevereiro de 2007, foi preparado um documento discutido por uma equipe composta pelo MEC, FNDE, INEP, Consultores (2), UNESCO e UNICEF, no total de 10 pessoas. O documento-base, resultado das discussões desse grupo, foi o precursor do Decreto $\mathrm{n}^{\circ}$ 6.094, de 24 de abril de 2007 (BRASIL, 2007a), e da Resolução FNDE no 029/2007 (BRASIL, 2007c). Robl (BRASIL, 2010) chama a atenção que basicamente o decreto trouxe alterações de nomenclatura, pois inicialmente o documento tratava de um "Programa Compromisso Todos pela Educação" e passou para "Plano de Metas Compromisso Todos pela Educação"; de Plano de Ação Global e Plano de Ações Integradas ficou Plano de Ações Articuladas; de Índice de Desenvolvimento da Educação (IDE) ficou Índice de Desenvolvimento da Educação Básica (IDEB).

O relato sobre o processo de discussão e de implantação do Plano de Metas Compromisso Todos pela Educação, feito pela consultora, revela que não contou com a participação dos sistemas estaduais e municipais de educação e isso pode explicar as alterações ocorridas na legislação após sua implantação. Trata-se de um grave equívoco, haja vista o regime federalista brasileiro e a Lei de Diretrizes e Bases da Educação Nacional (Lei no 9.394/96, BRASIL, 1996) que organiza a responsabilidade da oferta da educação entre os entes da federação. Portanto, sendo os municípios e estados entes com autonomia, é certo que uma política educacional conseguirá ser implantada nacionalmente por meio de indução da União no estabelecimento de acordos e convênios com os entes da federação.

Mas, além dessa origem do Compromisso (e do PAR) explicitada pela Consultora do MEC como relacionada à iniciativa do então presidente do FNDE Daniel Balaban preocupado em atender à totalidade dos municípios com assistência técnica e financeira, pode-se afirmar que há outras preocupações na pauta do MEC/FNDE. Por exemplo, a aplicação do Fundo de Manutenção e Desenvolvimento da Educação Básica e de Valorização dos Profissionais da Educação (Fundeb) leva à necessidade de maior controle da União. De 
acordo com Sena (2013), a adoção de fundos contábeis para o financiamento da educação básica (Fundef e, posteriormente, Fundeb), constitui exemplo de indução ao regime de colaboração. Tais medidas sugerem a necessidade de maior controle, haja vista a complexidade que envolve o Fundeb tanto em termos de extensão - para toda a educação básica - quanto na determinação de valores diferentes por cada etapa de ensino. Ademais, o próprio MEC reconhecia que o montante de recursos era insuficiente para impactar na melhoria da educação básica no País e estava disposto a suplementar os valores para municípios mais prejudicados. O PAR, dessa maneira, é um instrumento que tinha chances de garantir um tratamento mais equilibrado e sob o controle da União.

É curioso que o Fundeb foi regulamentado pela Lei $\mathrm{n}^{\circ} 11.494$, de 20 de junho de 2007 (BRASIL, 2007e), exatamente no mesmo dia da Resolução FNDE 029, de 20 de junho de 2007.

No âmbito de cada Estado, equalizou-se a capacidade de investimento por aluno do governo estadual e dos respectivos governos municipais. Para os estados com menor capacidade de arrecadação, elevou-se, significativamente, a contribuição complementar aportada pela União. Aproximam-se, assim, os Estados mais pobres daqueles que têm potencial maior de investimento educacional. Houve ampliação do efeito redistributivo (SENA, 2013, p. 128).

Portanto, a criação do Compromisso seria mais uma estratégia de controle social, necessária para acompanhar a aplicação do Fundeb na manutenção e desenvolvimento da educação. As inovações trazidas pelo Fundeb como, por exemplo, a abrangência de toda a educação básica e a maior complementaridade de recursos da União, sendo até $10 \%$ podendo ser utilizada por meio de programas direcionados para a melhoria da qualidade da educação básica, passaram a exigir um controle maior do MEC/FNDE. Nessa direção, sabendo que o Fundeb representava ainda poucos recursos para atender à melhoria da totalidade da educação básica, o MEC/FNDE criou um dispositivo de financiamento (por meio de planejamento participativo) de transferências voluntárias que podem ser canceladas a qualquer momento de acordo com a receita da União ou por interesse político-partidário, com a vantagem de ter um controle sistêmico por meio do IDEB.

Por fim, há de se destacar que a implantação do Compromisso e a adesão voluntária dos entes da federação aconteceram por via da obrigação de participação da Prova Brasil, tornando-a, assim, uma avaliação aplicada em todas as escolas do País. No mínimo, isso dá ao MEC/INEP um banco de dados com informações preciosas 
de toda a rede de ensino do país. Mais que isso, com a universalização da Prova Brasil, o MEC consegue acompanhar o desenvolvimento da rede de ensino e estabelecer "ranqueamentos" entre as escolas por meio do IDEB.

Com todas essas variáveis para análise, o que se pode inferir é que a utilização da técnica do planejamento (sua nova centralidade) se apresenta como uma ferramenta imprescindível para a operacionalização do conjunto de políticas educacionais que aportaram uma ampliação do fundo público para o ingresso dos sistemas educacionais em um novo patamar de desenvolvimento que supere os históricos problemas de acesso, permanência e de qualidade do ensino.

Segundo o livro do PDE (BRASIL, 2007b), a União passou a assumir mais compromissos perante os estados, os municípios e o Distrito Federal, para, respeitando os princípios federativos, dar unidade ao desenvolvimento da educação e corrigir as distorções que geram desigualdades. Nas palavras do Ministro Haddad,

O PAR é, portanto, multidimensional e sua temporalidade o protege daquilo que tem sido o maior impeditivo do desenvolvimento do regime de colaboração: a descontinuidade das ações, a destruição da memória do que foi adotado, a reinvenção, a cada troca de equipe, do que já foi inventado. Em outras palavras, a intermitência. Só assim se torna possível estabelecer metas de qualidade de longo prazo para que cada escola ou rede de ensino tome a si como parâmetro e encontre apoio para seu desenvolvimento institucional (BRASIL, 2007b, p. 24).

Pela síntese feita até aqui buscando descrever o nascimento da política de planejamento educacional no governo Lula da Silva, observa-se que, no segundo governo Lula, passou a existir um plano - Plano de Metas Compromisso Todos pela Educação - produzido por um grupo pequeno de técnicos supostamente sensibilizados em torno da resolução de problemas identificados na prática política. Em seguida, no mesmo ano de 2007, o então Ministro da Educação Fernando Haddad divulgou um livro sobre o Plano de Desenvolvimento da Educação (PDE), explicitando as razões, princípios e os programas implantados para alcançar a melhoria da qualidade da educação. É importante ressaltar que o PDE parte de uma concepção de educação que perpassa a execução dos programas, reconhecendo-a como uma face do processo dialético que se estabelece entre socialização e individuação da pessoa, que tem como objetivo a construção da autonomia, isto é, a formação de indivíduos capazes de assumir uma postura crítica e criativa frente ao mundo. Nessa perspectiva, o PDE propõe 
enfrentar estruturalmente a desigualdade de oportunidades educacionais no país, entendendo, dessa forma, a necessidade de reduzir as desigualdades sociais e regionais como ação de um plano nacional. Nesse plano, o governo Lula lançou o Plano de Aceleração do Crescimento (PAC), com medidas orientadas para a expansão da economia brasileira por meio da elevação dos investimentos em infraestrutura no período de 2007 a 2010. O PAC contemplou, ainda, medidas para melhorar o ambiente de negócios, bem como diretrizes e parâmetros macroeconômicos. Até hoje, o PAC é muito polemizado pela baixa capacidade de realização e restrição no investimento. Os críticos do PDE consideraram o PDE como o PAC da educação.

Educação sistêmica, ordenação territorial e desenvolvimento são princípios do PDE. O enlace entre educação, território e desenvolvimento deve ser um de seus resultados. Qualidade, equidade e potencialidade são seus propósitos. Qualidade entendida como enriquecimento do processo educacional, participação dos sujeitos e valorização das diferenças, de modo que as oportunidades educacionais se constituam em formas reais de reconhecimento e desenvolvimento das potencialidades, conhecimentos e competências. A melhoria da qualidade da educação e a redução de desigualdades relativas às oportunidades educacionais - em outras palavras, o direito de aprender - são suas razões constitutivas (BRASIL, 2007b, p. 40).

O importante a se destacar é que a retomada da prática de planejamento no segundo governo Lula aponta para uma realidade inovadora, no sentido de firmar o Estado com a responsabilidade de ofertar a educação pública de qualidade. Mas, se a inovação se materializa na prática social é uma questão a ser investigada com o uso de procedimentos científicos assentados no contexto da federação brasileira, conhecido pelas práticas tradicionais de concorrência territorial e de patrimonialismo. Nessa direção, um questionamento deve ser colocado para reflexão na próxima seção deste artigo: é possível um planejamento educacional, como o formalizado pelo Compromisso, contribuir para o desejado e necessário equilíbrio federativo? A análise será desenvolvida a partir de um estudo de caso: a implantação do PAR no Espírito Santo.

\section{A implantação do PAR no Espírito Santo}

O PAR chegou no Espírito Santo por meio da descentralização de recursos do MEC/FNDE para a Universidade Federal do Espírito Santo (UFES), no ano de 2007, com início da aplicação dos instrumentos do diagnóstico e do plano de metas 
no mês de fevereiro de 2008 em 24 municípios avaliados com baixo IDEB ${ }^{1}$. A equipe da UFES recebeu um curso de treinamento sobre o PAR de um consultor enviado pelo FNDE, pois, neste momento (outubro/2007), a equipe do MEC/ FNDE já havia chegado à conclusão de que a contratação de 42 consultores para atender o campo se tornou uma ideia difícil de ser concretizada.

De acordo com relatos coletados com professores que participaram da equipe da UFES, eles foram distribuídos entre os 24 municípios, ficando dois dias em cada um para a realização do PAR com suas etapas do diagnóstico e plano de metas. As dificuldades sofridas pelas equipes foram grandes devido ao fato do sinal de internet em muitos municípios ser fraco e irregular. Ademais, as dificuldades maiores foram encontradas na ausência da equipe local do município na prática do planejamento e da participação na gestão da educação municipal. Isto é, a maioria dos técnicos ou os demais integrantes do grupo convocado para discutir o PAR, não apresentavam conhecimento suficiente sobre a rede de ensino e nem mesmo possuíam a dimensão das necessidades das escolas. Outro ponto avaliado de forma negativa pela equipe da UFES se trata do tempo curto para a realização do PAR em cada município (dois dias), o que fez aligeirar as discussões e conferir ações mais pragmáticas. Por exemplo, o grupo local selecionava todos os cursos de formação (e eram muitos), independentemente de se precisavam ou se seriam viáveis de acontecer no contexto escolar, pelo simples fato de não se recusar nada que venha do MEC.

Os dados aqui apresentados foram coletados por meio de entrevistas e de grupos focais com diversos atores, todos eles técnicos que atuam na implantação do PAR tanto em Brasília quanto no Espírito Santo.

Em momentos diferentes de entrevistas com técnicos do FNDE, a maioria dos relatos sobre a criação do PAR reproduz o registro da consultora Robl (BRASIL, 2010) de que havia uma avaliação feita por técnicos do FNDE sobre a prática de recebimento de projetos isolados por municípios que já haviam adquirido certa expertise. Além dessa avaliação, também houve um depoimento que descreveu como motivação da elaboração do programa os desafios colocados pelo Plano Nacional de Educação (PNE 2001-2011) e o PAR era uma possibilidade de provocar uma sinergia entre o MEC, FNDE e outras autarquias.

Já nos depoimentos coletados em entrevistas com técnicos do MEC, não houve referência à origem ou à importância do PAR, sendo o tratamento dado pautado

Água Doce do Norte, Alto Rio Novo, Apiaca, Boa Esperança, Conceição da Barra, Conceição do Castelo, Dores do Rio Preto, Ecoporanga, Guaçui, Guarapari, Ibitirama, Irupi, Itapemirim, Iuna, Marataizes, Mimoso do Sul, Montanha, Mucurici, Muqui, Pedro Canário, Ponto Belo, Santa Maria de Jeribá, Viana. 
mais em ações de caráter eminentemente burocrático, como procedimentos e dinâmica instaurada de acompanhamento dos projetos. Observou-se, nas visitas ao MEC, uma mudança constante nos técnicos responsáveis pelo PAR, além de uma equipe pequena composta por cinco ou seis técnicos instalados em uma sala com telefones e computadores para atendimento aos municípios.

Talvez seja por isso que os técnicos entrevistados nos municípios informaram que os contatos, como as orientações em relação ao preenchimento do PAR e ao acompanhamento, eram realizados com o FNDE. Por isso também que se pode observar que os técnicos do FNDE possuem uma visão mais ampla dos problemas vivenciados pelos municípios. Por exemplo, foram os técnicos do FNDE que fizeram menção de forma mais acentuada sobre a percepção do trabalho nas secretarias municipais: falta de rotina de trabalho; falta de informação sobre o funcionamento da educação do município e sobre o Compromisso; reclamações sobre as senhas restritas do SIMEC que impedem uma maior visualização sobre o preenchimento e acompanhamento do PAR etc. Pode-se afirmar que a centralização dos recursos facilitou a primazia técnica do FNDE nos assuntos pedagógicos de responsabilidade do MEC e dos sistemas educativos.

Já na análise do documento "Questões importantes sobre o preenchimento do PAR municipal 2011 - 2014 (4 versão)" (BRASIL, 2011), as orientações enviadas para os municípios são de caráter instrumental, conforme indica a citação abaixo.

A equipe técnica do PAR está analisando alguns diagnósticos já elaborados pelos municípios com vistas a identificar as dificuldades que os municípios estão encontrando na elaboração autônoma do Plano de Ações Articuladas. Nesse sentido, consolidou-se o presente documento como mais um instrumento de apoio técnico aos municípios (BRASIL, 2011, p. 2).

No documento, as orientações trazem questões básicas como, por exemplo, o acesso ao sistema, tipo de navegador e como localizar o prédio no mapa da internet. Após isso, há um apelo à importância da ação de planejar e que seja de forma participativa. Ressalta que o Comitê local não tem um caráter de órgão fiscalizador e que esse comitê é diferente da equipe local.

A equipe local é um grupo de pessoas representantes de diversos setores da educação local, conforme apontado anteriormente. Todas elas devem estar presentes nas diversas fases de elaboração do planejamento. Os dados de todos os integrantes da equipe local 
devem ser registrados na aba "Equipe Local" nos "Dados da Unidade". Duas pessoas apenas não compõem uma equipe local para elaboração do PAR.

É importante que essa equipe tenha um planejamento de reuniões periódicas para obter informações sobre a execução das ações/subações do PAR, bem como fornecer subsídios para o monitoramento (BRASIL, 2011, p. 7).

Pode-se observar também um procedimento identificado pela equipe do MEC/FNDE sobre a feitura do PAR: "o PAR é um instrumento que privilegia a ação participativa, não deve ser elaborado e preenchido por apenas uma pessoa, seja ela um técnico da secretaria de educação ou uma pessoa contratada para esse fim" (BRASIL, 2011, p. 7). E, alerta:

O MEC não incentiva a contratação de consultores para elaboração do PAR. O pagamento de intermediários, que muitas vezes não conhecem a realidade do município, poderia ser um gasto inútil e, o que seria ainda pior, poderia impedir a comunicação direta entre o MEC e o gestor municipal (BRASIL, 2011, p. 8).

Após essas observações, o documento apresenta alguns exemplos retirados do PAR de municípios analisados (sem identificação), para mostrar equívocos cometidos: alerta para erros ortográficos cometidos e para a falta de detalhamento das informações no campo da justificativa, existente em cada ação/subação.

A justificativa deve ser clara e detalhada, fornecendo informações e elementos suficientes acerca da situação municipal referente ao indicador. Devem ser evitadas respostas pouco esclarecedoras. Quem acessar o PAR do município deve compreender de forma exata sua realidade educacional mediante a resposta fornecida (BRASIL, 2011, p. 9).

Nas entrevistas realizadas nos dois municípios de pequeno porte com os técnicos responsáveis pela elaboração e acompanhamento do PAR, foi observado que há uma falta de estrutura no trabalho desses técnicos no que diz respeito ao tamanho da equipe municipal, geralmente composta de um ou dois profissionais, que cumprem outras tantas tarefas além do PAR. Ademais, nos três anos de realização da pesquisa, apenas em um município houve permanência do técnico dentre os quatro pesquisados. Outro agravante se trata do tempo exíguo de realização do diagnóstico da educação municipal e do preenchimento do PAR. No primeiro PAR (2007-2010), foram dois dias destinados à tarefa coletiva; no PAR 
2011-2014, conforme a fala de uma técnica, "o novo diagnóstico foi uma coisa feita às pressas. Foi realizada em 24 horas divididas em três dias de reuniões" (ADN, 2012). Ou seja, os prazos impostos pelo MEC/FNDE para as secretarias municipais de educação são curtos e essa dinâmica se agrava na medida em que a rotina de trabalho dos técnicos é fragmentada e sem planejamento, muitas vezes é uma rotina padronizada por atender "eventos" pressionados pelos conhecidos problemas das escolas ou mesmo por demandas político-partidárias. Todos esses fatores acima apresentados podem influenciar no cometimento de equívocos como apontados no documento do MEC (BRASIL, 2011).

Ademais, a fase do diagnóstico e de elaboração do instrumento do PAR, de acordo com os entrevistados das secretarias municipais, contou com a participação de representantes de professores, diretores de escola, Ministério Público, Conselho Tutelar, do Conselho Municipal e da comunidade. Todavia, esse caráter participativo não permanece e nem é reconhecido no cotidiano de execução do PAR. Nos três municípios que tiveram suas equipes alteradas, apenas na capital, não obstante a mudança de partido político da gestão, revelou certa continuidade na ação de executar o PAR a partir da retomada do realizado pela equipe anterior. Pode-se inferir que a questão político-partidária interfere no processo, mas quando há uma organização do trabalho mais bem consolidada, a secretaria municipal de educação apresenta uma performance mais equilibrada em termos de reconhecer os programas educacionais e dar continuidade.

Tendo em vista que o diagnóstico do PAR é feito no ano anterior da eleição municipal, isto é, o novo dirigente terá que executar o planejamento feito pelo prefeito anterior, há um forte risco de tensões e de paralisação de determinadas ações previstas para o período. Esse problema foi reconhecido nas entrevistas com os técnicos dos municípios participantes da amostra que revelaram dificuldades em dar continuidade ao PAR sob a justificativa, da maioria, de que o diagnóstico não traduzia os problemas encontrados. Realmente, alguns técnicos informaram que na primeira edição do PAR, pelo fato de não entenderem e de desconfiarem da proposta do MEC, responderam ao diagnóstico de forma mais positiva no sentido de se protegerem de qualquer possível represália. É curioso observar que o fato de os municípios serem autônomos não os impede de estabelecer uma relação submissa com a União. Ou seja, há muitas variáveis que interferem na dinâmica do trabalho dos sistemas educativos e a ideia de planejar ainda é muito incipiente, sobretudo nos municípios que ainda não se constituíram como sistema.

Atualmente, no Espírito Santo, o PAR é uma política coordenada pela Undime em parceria com a Secretaria de Estado da Educação (SEDU). Em entrevista 
com a secretária executiva da Undime, foi informado alguns descompassos entre os municípios na elaboração do PAR. As três fases do PAR - diagnóstico, preenchimento e envio das ações e avaliação da equipe do SIMEC - são executadas de formas variadas pelos 78 municípios do estado. Enquanto alguns, em 2012, já estavam na fase da análise do SIMEC, outros ainda não haviam terminado o diagnóstico. Por sua vez, a secretária executiva considera que o PAR representa o enfrentamento de desafios na busca de alinhar as políticas entre os três poderes (União, estado e município). Ainda afirmou que o PAR "inibiu um pouco a questão da descontinuidade", porém pode acontecer mudança na equipe técnica e o desenvolvimento do PAR iniciado na gestão anterior pode não ser operado pela gestão atual. A questão da descontinuidade na execução dos programas na educação também é um tema de debate na Undime, que busca superá-la por meio das formações realizadas nas regiões do estado para orientação sobre o PAR.

Já o caso de Vitória, capital do estado, a secretária executiva da Undime considera uma exceção, pois o município "desconsidera o que vem do MEC".

Vitória tem uma equipe de planejamento grande e competente, mas não valoriza o PAR, tanto que o PAR do município ainda está em fase de elaboração, e o planejamento municipal se sobrepõe ao PAR. No entanto, deveria acontecer o contrário, Vitória, por ser capital, pela expressividade técnica e financeira no estado, deveria ser uma referência para os outros municípios. Mas o que prevalece é a distância dos técnicos de educação da capital, e a tentativa de autonomia e independência, em relação ao MEC e aos outros municípios (Entrevista Undime, 2012).

Em entrevista realizada com técnica da Secretaria Municipal de Educação de Vitória (SEME-Vitória), no ano de 2011, foi destacado que a capital tem seu planejamento próprio, mas que o articula com o PAR. Inclusive, afirmou que a secretaria toma cuidado para não deixar coincidir uma ação que recebe apoio do PAR com uma existente no planejamento do município, para evitar o investimento de recursos próprios e fazer uso do apoio da União. Segundo a técnica, mais de $70 \%$ das ações previstas no PAR foram executadas.

A técnica da SEME-Vitória afirmou que seu contato é maior com o FNDE, onde consegue receber as orientações necessárias para operar o SIMEC. Ademais, ressaltou que fazer a execução e monitorar o PAR pelo SIMEC exige maior qualificação e domínio da tecnologia. Dessa forma, entende 
que nas localidades onde as secretarias não são constituídas de profissionais qualificados, é provável que fiquem defasadas no recebimento de apoio técnico e financeiro por deficiência na comunicação com o MEC. A técnica avalia que a ausência do MEC dificulta o trabalho de muitas secretarias de educação. Ademais, criticou o instrumento do diagnóstico como fechado e não atende a totalidade da realidade do município.

Quando perguntada sobre a opinião dos diretores e professores das escolas sobre o PAR, a técnica afirmou que eles não reconhecem o PAR como um programa que financia as melhorias que acontecem na escola. Pois, segundo a técnica, os diretores não conseguem passar do planejamento e a secretaria monitora à medida que as escolas procuram. Nos grupos focais que contaram com a presença de diretores de escola, essa impressão foi confirmada sobre a falta de conhecimento do PAR, pois eles se reportam mais ao PDE-Escola.

Já em 2013, em outro momento de coleta de dados, houve a participação de outra técnica responsável pelo PAR, já que a eleição trouxe um novo partido político na frente da prefeitura de Vitória. Nessa gestão, a técnica considera que há uma boa parceria com a SEDU na discussão sobre o PAR e que é possível ocorrer a continuidade da política, que os sinais até agora apontam para isso com as reuniões do grupo. O que precisam é de um tempo maior para se apropriarem melhor dos detalhes.

O mesmo otimismo não se encontra em Vila Velha após frequentes mudanças na gestão do município e em número maior na pasta da secretaria de educação.

Acho que o grande problema é exatamente esse, a gente vem de um período de gestão política em que houve quatro secretários da educação, quatro políticas de educação, quatro linhas e quatro visões. Então, são quatro divisões. Isso é muito complicado! Uma vez posto, nós assumimos e, durante todo esse período, que estamos até agora observando as ações que efetivamente já foram criadas, efetivadas e tal, e as outras ações que estão por concluir, na verdade é pelo menos nosso objetivo. Aquilo que é da nossa gestão e que a gente arca certamente com o interesse de continuar, com conviç̧ões políticas. Infelizmente nem tudo que foi planejado tem sido dinamizado, mas retornamos os trabalhos do PAR, estamos na fase da atualização, e vamos concluir agora para poder fazer as exceções das atualizações do PAR. Mas, é uma tarefa difícil! (Técnico da Secretaria). 
Não obstante esses problemas, o técnico da Secretaria de Educação de Vila Velha considerou que a existência do PAR ajudou a equipe a fazer planejamento, pois considera o instrumento muito bom e atende bem a realidade do município. Mas, os técnicos tecem críticas ao excesso de burocracia do FNDE com exigências de difícil tramitação, levando muitas vezes à devolução de recursos financeiros.

A Secretaria de Estado da Educação (SEDU), por sua vez, acompanha o PAR dos municípios junto com a Undime. De acordo com as entrevistas realizadas com os técnicos do planejamento, os municípios pequenos procuram a SEDU para orientações. Ao mesmo tempo, a SEDU não tem acesso ao PAR dos municípios e geralmente não conhece as ações planejadas. A avaliação é de que o PAR proporcionou a troca de experiências e busca padronizar a rede de ensino no país, pois o FNDE exige o envio de projetos de construção, reforma ou mobiliário de acordo com normas fechadas. Mas, pode-se observar que o PAR estadual não tem muito significado no conjunto do trabalho realizado pela secretaria, pois os técnicos são instados a cumprir com o planejamento estratégico construído pelo governo estadual.

As impressões descritas sobre as entrevistas e grupos focais realizados levam a compreender que a implantação do PAR desde o ano de 2007, portanto com sete anos de experiência, se apresenta aos olhos dos técnicos das secretarias municipais e estadual de educação do Espírito Santo, como uma ferramenta interessante que os ajuda a encaminhar problemas observados na educação municipal. Ao mesmo tempo, as fragilidades são aparentes e percebidas na dificuldade de continuidade do PAR entre os governos; nos tempos exíguos postos pelo MEC/FNDE para exercer a atividade de diagnóstico e planejamento; na baixa capacidade técnica das equipes municipais combinada com o acúmulo de tarefas; na demora das equipes do MEC e do FNDE na devolução das dúvidas e das avaliações do PAR etc.

Tais problemas não devem levar à desistência e nem mesmo à inibição da política do PAR. Pelo contrário, é preciso entender que sete anos de execução ainda se configura como um curto tempo para o empreendimento de uma politica educacional e compreensão de seus resultados. Por outro lado, é importante corrigir os problemas identificados, procurando situar o PAR como um instrumento conhecido e reconhecido por todo o MEC e pelo FNDE, pois se observa que internamente ainda ocorrem ações desligadas ou que não são inseridas no PAR. Essa prática é contraditória se o PAR deve representar o planejamento da educação brasileira. Portanto, todos os programas e ações devem fazer parte do instrumento. Isso ajudaria os municípios a compreender a dinâmica do planejamento e estabelecer uma cultura de planejar. 
Essa prática implicaria também em evitar os "vícios" políticos imediatos de ajuda financeira isolada em acordo com interesses de algum político, pois os programas (e os recursos financeiros) devem constar do PAR, resultado de um diagnóstico elaborado via participação coletiva.

\section{Considerações finais}

As experiências e impressões retiradas dos dados coletados nesta pesquisa apresentam um cenário político da educação que remete à verificação da hipótese inicial de que o cumprimento do PAR é dependente de um equilíbrio na execução de ações centralizadoras e descentralizadoras de modo a favorecer o fortalecimento das competências dos municípios no planejamento educacional. Verificou-se que a prática dessa ação é muito precária devido a diversos elementos que se superpõem, tais como: a fragilidade financeira, técnica e política que vivem os municípios; as vicissitudes do poder local ainda envolto com práticas tradicionais de administração dos municípios; as intermitências da gestão do MEC combinadas com ações fragmentadas e pouco eficazes; a competência isolada do FNDE na gestão do PAR e o excesso de burocracia exigida para evitar os vícios de corrupção; a baixa capacidade técnica e política dos dirigentes das secretarias de educação e dos técnicos; o fato de as secretarias de educação não serem ainda ordenadoras de despesas, $o$ que as fazem desconhecer a aplicação financeira dos recursos educacionais; a baixa atratividade do PAR na secretaria de estado da educação, o que faz dele mais uma ação dentre outras mais importantes que constituem o planejamento estratégico etc.

Mesmo assim, a aplicação do PAR nos municípios trouxe uma nova estratégia de ação até então não vivenciada pela totalidade do sistema. Ao mesmo tempo, a exiguidade do tempo colocada pelo FNDE para o cumprimento das ações, destacada pelos entrevistados, provocou uma reação automática de "cumprimento de uma obrigação" sem a devida avaliação da capacidade de atendimento de cada sistema e das reais condições de aplicabilidade do plano. Desse modo, a implantação do PAR deu-se, em muitos casos, por improviso, sem levar em conta a debilidade das condições locais. Pressionados pelo imediatismo da racionalidade técnica, os entes se viram limitados quanto à "efetiva autonomia decisória e executiva, indispensáveis à descentralização e a formas mais democráticas de gestão" (OLIVEIRA, 2007, p. 16).

Importa ainda comentar sobre o acompanhamento do IDEB como referência para o sucesso do PAR. Os dados coletados sustentam a ideia de que esse parâmetro de avaliação é um engodo, pois não consegue retratar a complexidade vivenciada pelos sistemas educativos. $\mathrm{O}$ fato de os índices crescerem neste período não confirma, na materialidade da realidade dos sistemas observados, que houve melhoria do ensino. 
A partir dos questionamentos aqui elencados, fica a constatação de que, embora o PAR apresente uma proposta para estimular a participação dos entes que detêm a responsabilidade pela sua execução, alguns cuidados devem ser observados na relação entre o MEC e os executores locais para o cumprimento efetivo da proposta. Deve-se reconhecer que a implantação do PAR em sua plenitude é uma meta difícil de ser consolidada no isolamento de um sistema educativo. O que se almeja é o comprometimento da União em garantir efetivo regime de colaboração e o atendimento igualitário a todos os sistemas. Desse modo, cumpre-se o papel nuclear do Estado, no sentido de colaborar para a superação das dificuldades orçamentárias, gestionárias e pedagógicas que afligem os entes administrativos locais. Talvez assim, o planejamento educacional possa contribuir para o desejado equilíbrio federativo. 


\title{
Management of municipal education systems: Planning and federal balance in question
}

\begin{abstract}
This study aims to analyze the challenges of educational planning in management of the municipal education system. Specifically, the goal is to understand whether implementing the Joint Action Plan follows the trail of hegemony and centrality of the state and/or is a means of providing voice to civil society in the conduct of public management. A case study determines that PAR performance depends on a balance of centralizing and decentralizing execution of actions to strengthen municipalities' powers in educational planning. Moreover, it is essential to fulfill the state's central role, to collaborate on the budget, management and pedagogical difficulties affecting local administrative entities. Perhaps educational planning can contribute to the desired federal balance.
\end{abstract}

Keywords: Planning. PAR. Municipal education system.

\section{Gestión de los sistemas municipales de educación: la planificación y el equilibrio federal en cuestión}

\section{Resumen}

Este artículo tiene como objetivo analizar los desafios de la planificación educativa en la gestión del sistema de educación municipal. En concreto, el objetivo es entender si la conducta del Plan de Acción Articulada (PAR) sigue el camino de la hegemonía y la centralidad del Estado y / o es un medio de dar voz a la sociedad civil en el desarrollo de la gestión pública. A través de un estudio de caso, se observa que el rendimiento del PAR depende de un equilibrio entre la centralización y la descentralización de la ejecución de las acciones con el fin de promover el fortalecimiento de las competencias de los municipios en la planificación educativa. Por otra parte, para cumplir el papel central del Estado es esencial colaborar para superar las dificultades pedagógicas que afligen a las entidades administrativas locales. Talvez la planificación educativa pueda contribuir al equilibrio federal deseado.

Palabras clave: Planificación. PAR. Sistema de educación municipal. 


\section{Referências}

BRASIL. Decreto $n^{\circ}$ 6.094, de 24 de abril de 2007. Dispõe sobre a implementação do Plano de Metas Compromisso Todos pela Educação, pela União Federal, em regime de colaboração com Municípios, Distrito Federal e Estados, e a participação das famílias e da comunidade, mediante programas e ações de assistência técnica e financeira, visando a mobilização social pela melhoria da qualidade da educação básica. Diário Oficial da União. 25 abr. 2007 a.

. Lei $\mathrm{n}^{\circ}$ 9.394, de 20 de dezembro de 1996. Estabelece as diretrizes e bases da educação nacional. Diário Oficial da União. 23 dez. 1996.

. Lei $\mathrm{n}^{\mathrm{o}} 11.494$, de 20 de junho de 2007. Regulamenta o Fundo de Manutenção e Desenvolvimento da Educação Básica e de Valorização dos Profissionais da Educação - FUNDEB, de que trata o art. 60 do Ato das Disposições Constitucionais Transitórias; altera a Lei no 10.195 , de 14 de fevereiro de 2001; revoga dispositivos das Leis nos 9.424, de 24 de dezembro de 1996, 10.880, de 9 de junho de 2004, e 10.845, de 5 de março de 2004; e dá outras providências. Diário Oficial da União. 22 jun. 2007e.

. Ministério da Educação. Fundo Nacional de Desenvolvimento da Educação. Resolução/CD/FNDE/nº 029, de 20 de junho de 2007. Estabelece os critérios, os parâmetros e os procedimentos para a operacionalização da assistência financeira suplementar a projetos educacionais, no âmbito do Compromisso Todos pela Educação, no exercício de 2007. Diário Oficial da União. 29 jun. 2007c.

. Ministério da Educação. Fundo Nacional de Desenvolvimento da Educação. Resolução CD/FNDE n ${ }^{\circ}$ 47, de 2 de setembro de 2007. Altera a Resolução CD/FNDE n ${ }^{\circ}$ 29, de 20/7/2007, que estabelece os critérios, os parâmetros e os procedimentos para a operacionalização da assistência financeira suplementar e voluntária a projetos educacionais, no âmbito do Compromisso Todos pela Educação, no exercício de 2007. Brasília, DF, 2007d.

. Ministério da Educação e Cultura. Plano de Desenvolvimento da Educação: razões, princípios e programas. Brasília, DF, $2007 \mathrm{~b}$.

. Ministério da Educação e Cultura. Documento técnico contendo o histórico acerca da criação e implementação do Plano de Metas Compromisso Todos pela Educação e as perspectivas de continuidade. Brasilia, DF, 2010.

. Ministério da Educação e Cultura. Questões importantes sobre o preenchimento do PAR municipal 2011 - 2014. $4^{\mathrm{a}}$ versão, Brasília, DF, 2011. 
MARTINS, P. S. O financiamento da educação básica por meio de fundos contábeis: estratégia política para a equidade, a autonomia e o regime de colaboração entre os entes federados. Tese (Doutorado em Educação)Universidade de Brasília, Brasília DF, 2009.

OLIVEIRA, D. A. Regulação e avaliação de políticas públicas educacionais. In: DOURADO, L. (Org.). Políticas e gestão: novos marcos regulatórios da educação no Brasil. São Paulo: Xamã, 2007.

SAVIANI, D. Sistema nacional de educação: conceito, papel histórico e obstáculos para sua construção no Brasil. In: REUNIÃO ANUAL DA ANPED, 31., 2008, Caxambu. Rio de Janeiro: Associação Nacional de Pós-Graduação e Pesquisa em Educação, 2008. Disponível em: $<$ http://31reuniao.anped.org. $\mathrm{br} / 5$ trabalhos_encomendados/trabalho\%20encomendado\%20-\%20gt $05 \% 20$ -\%20dermeval\%20saviani.pdf>. Acesso em: 25 fev. 2014.

SENA, P. Planejamento educacional e federalismo no Brasil. In: FERREIRA, E. B.; FONSECA, M. Política e planejamento educacional no Brasil do século XXI. Brasília (DF): Liber, 2013. p. 102-23.

\section{Informações da autora}

Eliza Bartolozzi Ferreira: Doutora em Educação pela Universidade Federal de Minas Gerais, Brasil. Professora do Programa de Pós-Graduação em Educação da Universidade Federal do Espírito Santo, Brasil. Contato: eliza.bartolozzi@gmail.com 